\title{
Reports from the Field: Knowledge and Learning Applications in Practice
}

\author{
Dr. Julee Hafner, Chair \\ The Chicago School Of Professional Psychology \\ haf2lead@gmail.com
}

\author{
Dr. Alexander Kaiser, Co-Chair \\ Vienna University of Economics and Business \\ alexander.kaiser@wu.ac.at
}

\begin{abstract}
Welcome to this, the 53rd Hawaii International Conference on System Sciences (HICSS) conference. This Reports from the Field Minitrack, under the Knowledge Innovation and Entrepreneurial Systems Track, proudly brings you the latest research focused on the application of innovation of knowledge management issues as reported by both researchers and practitioners alike. With the focus on application, this minitrack helps practioners and theorists alike. It is here we examine how theory informs and impacts practice as well as how practice can influence theory from the practioner perspective.
\end{abstract}

\section{Introduction}

How do our theories on knowledge management and organizational learning contribute to real-world applications? Although there are many journals that focus on KM topics in systems-oriented research, theory development is at risk of becoming isolated from practical application. The needs and experiences of knowledge workers, who develop, implement, manage, and use knowledge management systems are at risk. It is within this divide between the knowledge systems research being conducted, and the needs and experiences of these knowledge workers that this minitrack is focused.

These practitioners in the field can provide invaluable insight to the research community in terms of practical application skills. It is important to be aware that there are countless practical perspectives on how to initiate, coordinate and monitor organizational learning processes.
The goal of this minitrack is to provide this "bridge" between the knowledge management and organizational learning academic scholars that build theory and the systems practitioner community. This mini-track encourages a focus upon how theory informs and impacts practice as well as how practice can influence theory.

In Reports From The Field, we are devoted to providing new research avenue to conduct research for building theory while improving the application of results to knowledge management systems in the practitioner community. It is hoped that accepted submissions will document specific knowledge system successes and failures within organizations from a practitioner perspective.

\section{Yi-Ting Wang, Travis Huang, and Kuan-Yu Lin}

Three authors will start off the presentations, YiTing Wang, Kuan-Yu Lin, Travis Huang, will present, "Why people adopt VR English language learning systems: An extended perspective of task-technology fit".

The paper addresses the impact of VRcharacteristics in a learning environment on the adoption of this technology. The authors follow the research question: What factors can influence the learner's willingness to use VR, in order to achieve the learning outcomes, so that they can grasp the learner's attention. of knowledge flow dynamics in context.

They use a modified version of the TaskTechnology-Fit-Model to explore this question using a survey study in a virtual learning environment. They identified significant motivational and technological characteristics that influence the fit between technology and needs. This fit on the other hand impacts satisfaction and intention to use. 


\section{Florian Fahrenbach, Alexander Kaiser, and, Andreas Schnider}

For our final submission, three authors will present their submission, "Introducing an Artifact for the Assessment of Transversal Professional Competences". This is an ongoing work in the body of knowledge in the area of professional competency design and assessment within the trades.

However, this paper departs from a project conducted with the Trade and Craft sector of the Austrian Federal Chamber of Economics. A design science perspective scaffolds the development of an artifact, the net of competences, to support the assessment of transversal professional competences in the validation of prior formal, non-formal and informal learning. It asks the question, "How to assess transversal professional competencies?".

To answer this question, we describe the design of a self-assessment by outlining item generation, generation of verb levels and the triangulation of items and verbs to create nodes in the net of competences.

\section{Conclusion}

We wish to thank each of our presenters for their research and willingness to share their results with us during another year of celebration at HICSS-53. As the Knowledge Innovation and Entrepreneurial Systems
Track continues to grow, we invite new researchers to submit applied papers that contribute to the knowledge of this exciting area, Reports from the Field. With continues emphasis on application, we encourage all practioners and theorists to contribute to the body of knowledge and contribute to many great discussions at HICSS.

We look forward seeing new research studies that contribute to application of Knowledge Management to organizations, and entrepreneurs and solopreneurs within the business and industrial community. We hope researchers will consider contributing to our mini-track, Reports from the Field next year.

\section{Chairs}

Dr. Julee Hafner (Primary Contact)

The Chicago School of Professional Psychology

325 N Wells St., Chicago, Ill 60654

Fax: +1 (321)-632-5112

Phone: +1 (321)-720-7280

E-Mail: haf2lead@gmail.com

Dr. Alexander Kaiser

Vienna University of Economics and Business

Phone: +43-676-3987663

E-Mail: alexander.kaiser@wu.ac.at 